\title{
Epistemologia da Psicanálise ${ }^{140}$ \\ Elementos para o debate
}

\section{Renato Mezan 141}

1. A epistemologia se ocupa da estrutura de uma disciplina científica, isto é, da(s) maneira(s) como seu objeto é recortado no real, como se formam seus conceitos e hipóteses, seus procedimentos de argumentação, de validação ou refutação de enunciados no campo desta disciplina, etc.

2. A Psicanálise é constituída por dois grandes ramos, cujas relações podem ser investigadas com os recursos oferecidos pela epistemologia. São eles: primeiro, uma teoria geral do psiquismo, da sua evolução rumo a alguma maturidade, do seu funcionamento normal e patológico, e dos meios possíveis de intervir nesse último; segundo, uma prática clínica orientada por essa teoria. É o que, em outras palavras, Freud afirma no verbete que escreveu, em 1923, para a Enciclopédia Britânica.

3. Portanto, a epistemologia da Psicanálise tem por objeto tanto a dimensão teórica quanto a dimensão prática, e uma das suas tarefas é estudar a relação entre ambas, por si mesma, como sabemos, bastante complexa, porque envolve diversos fatores que se sobredeteriminam uns aos outros.

4. Porém ela não pertence, a meu ver, à Psicanálise stricto sensu, e sim à filosofia da ciência. Ou seja, ela está para a teoria psicanalítica como esta está para o trabalho do analista, seja ele de natureza clínica ou teórica. O material para esse estudo é constituído, em geral, pelos textos nos quais a teoria é ou foi construída, mas também pela "dissecação" de material clínico por meio de instrumentos, como a Grade de Bion, a escuta da "situação transferencial total" recomendada por Melanie Klein, a leitura através da dialética impulsos/defesas na tradição freudiana, etc.

5. Contudo, como o objeto da Psicanálise é a vida psíquica em todas as suas vertentes (inclusive no plano cultural e social), é preciso encontrar, na

\footnotetext{
140 Trabalho apresentado na mesa "Psicanálise e Epistemologia em pauta" no II Simpósio Bienal SBPSP "Fronteiras da Psicanálise: a clínica em movimento" no dia 29 de agosto de 2020.

${ }^{141}$ Psicanalista, membro do Departamento de Psicanálise do Instituo Sedes Sapientiae, professor titular da PUC-SP, coordenador da revista Percurso, autor de vários livros.
} 
epistemologia da Psicanálise, um lugar para a subjetividade do autor cuja obra estamos examinando. Neste caso, a análise epistemológica pode e deve ser complementada por uma abordagem histórica, que situe essa obra nos seus vários contextos: a época em que foi escrita, o estado da arte naquele momento, quais problemas eram discutidos e por que, a solução proposta pelo autor para aqueles que o interessavam, eventualmente contra quais posições então existentes sobre o tema, etc.

6. Uma das áreas nas quais as proposições da epistemologia da Psicanálise podem ser diretamente úteis para o analista em seu trabalho clínico é, a meu ver, a supervisão. $O$ ponto de enlace entre o caráter geral delas e a singularidade do caso em exame é o que podemos denominar raciocínio clínico. Este subjaz às interpretações pontuais e às construções que vão sendo propostas pelo analista, e consiste na subsunção do conteúdo singular em pauta sob as diversas classes de possíveis propostas pela teoria. Tal conteúdo pode ser o discurso do paciente em sessão (em seus vários aspectos: a fantasia inconsciente que pode estar sustentando, o tipo de angústia que ela suscita, a(s) defesas a que parece estar submetida, o gênero de transferência que tudo isso pode sugerir, etc.), a reação do analista a esses vários fatores (contratransferência), ou ainda o modo de relação entre os dois protagonistas possivelmente vigente no momento ("pensamento do par", segundo André Green).

7. De qualquer modo, alguma familiaridade com o modo de construção, de funcionamento e de utilização da teoria me parece essencial para que possamos nos orientar naquilo de que ela trata, isto é, a imensa complexidade da vida psíquica do ser humano. A situação analítica - pelos efeitos dinâmicos da sua estrutura - é um revelador privilegiado dessa complexidade: por isso, vale para ela o aforisma de Kant na Crítica da Razão Pura: intuições sem conceitos são cegas, conceitos sem intuição são vazios. Em outros termos: sem a bússola metapsicológica (cujo funcionamento é esclarecido pela Epistemologia da Psicanálise) não temos como nos orientar em meio a essa complexidade. É por isso que a situação de supervisão pode favorecer que ambos - supervisionando e supervisor - exercitem o raciocínio clinico em condições excepcionalmente favoráveis (porque não submetidas ao "calor da hora"), e, com isso, possam dispor de instrumentos mais precisos para o exercício da prática quotidiana. 


\section{Três sugestões para reflexão: Psicanálise e Epistemologia ${ }^{142}$}

\section{Elias M. da Rocha Barros 143}

Gostaria de iniciar agradecendo o convite da Silvana Rea e a coordenação da Suzanne Gallo.

Tenho apenas 15 minutos para introduzir nosso assunto. Não é tempo suficiente para apresentar uma construção complexa a qual nem sei se sou capaz. Então me limitarei a introduzir três propostas de reflexões disparadoras de uma conversa.

Não sou um especialista em epistemologia da Psicanálise e nem escrevi qualquer trabalho sobre o assunto. Assim pedirei a vocês que me ouvem ou me leem, que me permitam tomar a liberdade de compartilhar com vocês, pensamentos de outros autores (e até abusar de citações) que tem um raro poder de síntese capaz de expressar a essência daquilo que gostaria de lhes transmitir.

Então, nestas condições, por que estou nesta mesa? André Green em diversas ocasiões disse que o maior inimigo da psicanálise não era a concepção organicista e sim a superficialidade e a irrelevância com a qual seus conceitos são apresentados seja quando os analistas pretendem introduzir inovações sem respeitar a complexa articulação conceitual do campo, seja quando tentam propor aquilo que consideram ser o campo comum entre as diversas abordagens. Também dizia que a descrição de estados e vivências conscientes transvestidos de conceitos psicanalíticos, não torna este conhecimento autenticamente psicanalítico.

Sempre procuro chamar a atenção de meus alunos no início de meus seminários sobre as qualidades que devem estar presentes para que tenhamos abordagens confiáveis do Inconsciente e para podermos debater teorias e experiências clínicas. Não é qualquer afirmação que permite uma reflexão.

Estou muito feliz em estar ao lado de Renato Mezan autor de vários trabalhos, mas especialmente do seminal O Tronco e os Ramos. Estudo histórico

\footnotetext{
142 Trabalho apresentado na mesa "Psicanálise e Epistemologia em pauta" no II Simpósio Bienal SBPSP "Fronteiras da Psicanálise: a clínica em movimento" no dia 29 de agosto de 2020.

143 Analista didata e docente da SBPSP, fellow da Sociedade Britânica de Psicanálise e de seu Instituto, prêmio Sigourney pela contribuição à Psicanálise.
} 
da Psicanálise (2014) um livro a ser estudado e relido algumas vezes e que considero uma das obras psicanalíticas mais importantes publicadas nos últimos 20 anos. Faço este comentário também a partir de minha experiência de muitos anos de trabalho no Dicionário Enciclopédico da Psicanálise em elaboração pela IPA.

Devo mencionar este livro hoje várias vezes tendo em vista que minha apresentação será inspirada nele e no livro Insight de Jorge Ahumada (2011). Vou privilegiar uma apresentação dialógica com o Mezan sem buscar uma originalidade própria. Se originalidade houver esta estará na maneira como combino as ideias que apresento e nas problemáticas delas derivadas a partir de minha experiência.

\section{Primeiro disparador}

Freud (1926 p.191) escreveu: "Ciência como se sabe, não é uma revelação; muito tempo depois de seus inícios faltam atributos à ela tais como limites definidos (defininess), imutabilidade e infalibilidade, atributos estes que o pensamento humano sempre buscou" .

Vejam, não quero desqualificar a ciência, nem nossas certezas probabilísticas (um paradoxo, evidentemente), nem me juntar àqueles que propagam uma equivocada definição dos princípios da relatividade.

Na Universidade de Princeton Athul Gawandi referiu-se aos conhecimentos médicos enfatizando um paradoxo ao falar das: "certezas incertas de uma ciência probabilística”. Gosto desta afirmação paradoxal que em parte repito aqui, embora não saiba localizar o texto no qual está observação foi feita.

Meu objetivo é circunscrever um campo em permanente transição baseado em probabilidades, em modelos úteis que são confiáveis para aprofundar nossa investigação desde que saibamos investigar a arquitetura de conceitos sobre as quais a teoria se assenta.

Esta frase contém expressões que merecem reflexão. Penso que a Psicanálise é um campo em permanente movimento de transição e que devemos estar sempre muito atentos a arquitetura dos conceitos sobre os quais ela se assenta para podermos refletir criticamente sobre como organizar nossas observações clínicas. 
O conhecimento que constitui o corpo da psicanálise foi adquirido sobretudo a partir de observações mais do que por meio de deduções.

A psicanalista anglo-canadense Elizabeth Spillius, uma querida saudosa amiga e mestra, uma vez falou do conceito de Wilderness (Lugar incerto, região selvagem), um conceito que visa capturar o espaço transicional no qual trafegam certos rituais e relações tribais de natureza ambígua. São conceitos ou coisas (things) que habitam uma encruzilhada entre natureza e cultura, por exemplo. Spillius usava o conceito transposto para a Psicanálise para se referir a situações "in-between", situações que existiam num espaço transicional do "nem lá, nem cá”, que capturavam momentos de transição. É um espaço onde são gerados conceitos-ponte e como tais precisam estar bem assentados para permitir uma travessia segura.

Mezan (2014, p. 50), no livro que mencionei, diz algo valioso sobre este espaço sempre em transição habitado pelo conhecimento psicanalítico. Diz: "Freud não coincide integralmente com Freud, as hipóteses regionais que elaborou ao longo de trinta ou quarenta anos de trabalho não se harmonizam sem resto, e é justamente esta diversidade interna à doutrina de base que alimenta $\mathrm{e}$ legitima o debate".

O conhecimento psicanalítico é transitório, mas sólido desde que seja sustentado por uma arquitetura conceitual bem articulada.

Há diversos modelos presentes na obra de Freud e na psicanálise. Nenhum modelo é uma simples continuação do anterior e a relação entre eles é sempre muito complexa (idem).

Tanto Freud quanto Klein derivaram seus constructos do trabalho clínico, que ocorre num ambiente privado, dual cujas evidências num primeiro momento só são compartilhadas pelo analista e por seu paciente. Todavia quando publicados estes conceitos adquirem uma certa rigidez fruto de formulações linguísticas e paradoxalmente, no início, estes conceitos buscavam capturar fenômenos que iam muito além daquilo que a linguagem podia descrever.

Vou recuar para ilustrar com um exemplo histórico, o que estou pretendendo comunicar (sem qualquer intenção de originalidade) sobre a articulação possível entre os diversos níveis nos quais os conceitos psicanalíticos são elaborados. O exemplo vem de um outro campo, isto é da matemática como linguagem e da Geometria como teoria. 
Na Mesopotâmia a matemática estava a serviço de resolução de questões concretas: divisão da terra depois das enchentes, projetos de irrigação, construção de edifícios etc. A regra baseada na divisão da corda em segmentos de 3-4 e 5, juntados pelas pontas, resultavam num ângulo reto, fechado num triângulo. Os sábios mesopotâmicos e babilônicos estavam interessados em questões práticas, não teóricas quando desenvolveram este conhecimento.

Pitágoras que passou duas décadas estudando no Oriente Médio antes de retornar a Samos e depois a Croton na Sicilia, foi quem então tornou a Geometria um constructo teórico. Tornou este conhecimento empírico baseado em observações com fins pragmáticos parte de uma teoria, a Geometria, baseado na regra 3,4 e 5. A partir daí este conhecimento passou a fazer parte de uma construção dedutiva e se tornou o princípio básico da matemática e da ciência ao elaborar o que hoje conhecemos como o Teorema de Pitágoras. Números e fatos neste campo passaram a se misturar desde então.

Quero lembrar que quando falamos em Metapsicologia em Psicanálise estamos falando inspirados numa das conotações da do termo Metafísica, ou seja, como algo além da Física, isto é, estamos nos baseando nos princípios (aporias?) sem os quais a Física não poderia existir.

Estou com esta menção reafirmando a complexidade do objeto psicanalítico e procurando chamar a atenção para a intrincada relação existente entre a observação e as subsequentes deduções.

\section{Segundo disparador}

Se tomarmos a sessão como nosso campo privilegiado de observação, onde estará o objeto psicanalítico? Em minha resposta estarei seguindo Green e numa perspectiva e linguajar diferentes, Bion e Ogden com tinturas Winnicotianas.

Estou ciente do perigo que corro ao associar linhas de pensamento baseadas em modelos bastante diferentes. Não estou preocupado em articular neste momento seus modelos, mas apenas em me referir ao que me parece uma perspectiva comum do quê observar na relação analítica.

Nas Conferências Brasileiras, Green (1990, p 31) pergunta-se onde está o objeto psicanalítico? No paciente ou no analista e responde: "Pois ele não está 
nem no analista, nem no paciente, está no espaço de reunião das trocas transferências/contra transferenciais”.

Hoje provavelmente descreveríamos este espaço clínico como aquele da intersubjetividade e encontraríamos um lugar para nos referirmos à reverie. Trata-se de um espaço transicional, de um lugar em movimento, do sendo. É neste campo que capturamos o material que nos proporcionará a oportunidade de construirmos modelos conceituais.

A título de exemplo do que quero comunicar, mencionarei que o Narcisismo é um conceito não é algo que esteja lá para ser observado. O que observo é um conjunto de relações que, desde que eu defina uma tópica (um espaço mental), o conceito de narcisismo me permite elaborar uma série de hipóteses que me permitem articular uma teia de outros conceitos.

\section{Terceiro disparador}

Quero agora me referir ao conceito de insight ostensivo proposto por Jorge Ahumada (2011).

O ostensivo foi proposto por Bertrand Russel como um qualificativo de um tipo de definição. Estas definições ostensivas referem-se a eventos que ocorreram para uma determinada pessoa, num determinado momento clínico básico que produz a transformação/mudança psíquica que é a própria essência do método na da clínica psicanalítica, base de observação para a construção de teorias psicanalíticas.

Este conceito baseado na observação daquilo que parece proporcionar uma transformação psíquica, oferece (a meu ver) uma ponte entre diversas perspectivas teóricas que me parece útil de ser explorada.

Em artigo recente (2019) Ogden a meu ver complementa e aprofunda esta questão ao propor distinguir entre o que denomina psicanálise

\section{epistemológica e psicanálise ontológica.}

A psicanálise epistemológica tem como principais autores Freud e Klein e está relacionada com conhecer e compreender o seu funcionamento psíquico. Ela é portadora de um conhecimento descritivo.

É curioso notar aqui a coincidência com o conceito de conhecimento por descrição proposto por Bertrand Russel (1929) em contraste com 
conhecimento por familiaridade. O conhecimento do primeiro tipo leva a um conhecimento direto do próprio objeto, a uma compreensão de seu funcionamento.

Conhecimento do segundo tipo, por familiaridade supões uma experiência pessoal com a constituição do próprio objeto, vai além do cognitivo. Neste caso o insight é baseado no que ela sente e vive, o objeto é definido ostensivamente para utilizar suas próprias palavras, o que leva Ahumada (1999) a enfatizar a importância do insight ostensivo como aquele que produz mudança psíquica.

A psicanálise ontológica tem como principais autores Winnicott e Bion e está relacionada com ser (being) e tornar-se (becoming). Ela visa tornar o paciente familiarizado com seu modo de ser e de se transformara partir de como está sendo e não como é. Ela é portadora de um conhecimento baseado na experiência. Aqui é importante enfatizar que não se trata de uma experiência estática, um momento fotográfico de como o paciente é, mas é melhor expresso pela imagem de um filme que se desenrola e é composto de milhares de imagens em movimento. Poderíamos dizer que o paciente se apreende no processo de transição do tornar-se sujeito.

Aqui, como dissemos acima, estamos falando de conhecimento por familiaridade e de insight ostensivo.

É claro que estes dois processos estão intimamente conectados e que é difícil separá-los nitidamente.

O insight ostensivo é a experiência de conhecer seu inconsciente no momento do sendo, num processo vivo de transição entre o saber como o sujeito se constitui como tal e adquire uma Eu-idade (I-ness) Esta experiência de tornar se sujeito através de um estado de ser é na imensa maioria das vezes desconhecida do paciente e Ogden até sugere que não é do domínio do imaginável. As expressões linguareiras disponíveis em português não favorecem a descrição destes dois estados.

Obrigado.

\section{Referências}

Ahumada, Jorge (1999). Descobertas e Refutações. A lógica do Pensamento Analítico. Rio de Janeiro: Imago. 
Ahumada, Jorge (2014). Insight . London: Routledge,

Mezan, Renato (2014). O Tronco e os Ramos. Estudo histórico da Psicanálise.

São Paulo: Companhia das Letras. 